\title{
Can lifestyle change and dietary control improve sexual dysfunction in sexually active men via visceral adiposity index?
}

Mustafa Bolat ( $\sim$ msbolat@gmail.com )

Medicana International https://orcid.org/0000-0002-4650-2271

Fatih Kocamanoğlu

Medicana International https://orcid.org/0000-0002-5136-5048

Latif Ozbek

Medicana International

Bekir Şahin

Medicana International

Merve Yilmaz

Medicana International

Salih Gümüş

Medicana International

Cihad Dündar

Medicana International

Ramazan Asci

Medicana International

Article

Keywords:

Posted Date: February 23rd, 2022

DOI: https://doi.org/10.21203/rs.3.rs-1363189/v1

License: (c) (1) This work is licensed under a Creative Commons Attribution 4.0 International License.

Read Full License 


\section{Abstract}

The metabolic syndrome (MeTS) negatively affects male sexual function. Lifestyle changes improve erectile function. However, the effects of lifestyle changes on sexual function in men with and without MeTS on the visceral adiposity index (VAl) have not been adequately investigated. Patients with MeTS ( $\mathrm{n}$ $=48)$ and those with no MeTS $(n=31)$ were recruited. Sexual functions and psychogenic status were assessed using the International Index of Erectile Dysfunction (IIEF) questionnaire and Beck's depression inventory (BDI), respectively. The VAI was calculated using the gender-specific formula. Demographic, clinical, biochemical and hormonal data were recorded. Participants were advised to 8500 steps per day and dietary control. At least three months later, demographic and biochemical tests were repeated, and the VAI was calculated. Association between sexual functions, presence of MeTS and lifestyle changes via the VAI were analyzed. Each integer increase of the VAI was related to a 1.74-fold increased risk of ED in the MeTS group. The MeTS was related to moderate to severe ED than those with no MeTS $(p=0.033)$. A $24 \%$ decrease of the VAl was recorded in the MeTS group at the end of the study $(p=0.014)$. The MeTS criteria were disappeared in eight patients at the end of the study, with a slight decrease of VAI $(p=0.07)$. In the beginning, patients with MeTS and no-MeTS showed similar sexual satisfaction, orgasm, desire, and general satisfaction scores. Sexual satisfaction, orgasm and general satisfaction were improved in the non-MeTS group $(p<0.05)$. At the end of the study, the MeTS group showed similar sexual satisfaction, desire, orgasm and general satisfaction rates $(p>0.05)$. Higher VAl levels were related to the lower erectile function scores, particularly in patients with MeTS. Lifestyle changes improved male sexual function scores only in the non-MeTS group. Therefore, fighting against MeTS should be adopted as a global healthcare policy.

\section{Introduction}

The male sexual function, including at least one of the components such as erectile function, sexual satisfaction, desire and orgasm, is a prevalent condition accompanied by chronic diseases [1]. Erectile dysfunction (ED) is one of the most common problems in men over 40 years of age. Reported prevalence is about $40 \%$ among men between $60-69$ years and almost up to $100 \%$ among men older than 70 years [2]. In addition to some acute disorders of psychogenic origin, chronic central and peripheral organic conditions generally alter the delicate balance of the erection mechanism [3]. For years, metabolic syndrome (MeTS) has been known as a common condition that negatively affects sexual function in men [4]. A recent analysis showed that in the United States, almost one-third of adults have the MeTS [5].

Although sexual dysfunction is a non-life-threatening condition, it can be a harbinger of a significant disease, especially when seen with complex pathologies such as MeTS. The MeTS have a progressive nature, which often results in cardiovascular complications unless effectively managed. An increase of adipose content leads to increased activity of inflammatory products such as cytokines, adipokines and fatty acids, disrupting the vascular endothelial mechanism, causing nitric oxide insufficiency and consequent sexual dysfunction in men [6]. Dyslipidemia causing endothelial dysfunction and inflammation also occurs with increasing frequency in men with increasing age [7]. Hypertension 
accelerates the atherosclerotic process, causing hypoxia in the end-organs [8]. Diabetes mellitus is another clinical condition that causes erectile dysfunction through decreased anti-inflammatory cytokine adiponectin and circulating testosterone (T) [9]. Increased burden of adipose tissue is closely associated with increased morbidity and mortality. Adipose tissue dysfunction, characterized by decreased adipocyte differentiation and angiogenesis, increases the inflammatory response in obese individuals [10]. As a result, the ED may be the first harbinger of underlying cardiovascular diseases. Although the ED can be treated with phosphodiesterase type 5 inhibitors (PDE5is), these agents do not have an additive effect on vascular dysfunction in the long term [11].

The concept of visceral adiposity index (VAI), as an indicator of adipose tissue dysfunction, was first introduced, combining HDL cholesterol, triglyceride, BMI and WC in a gender-specific formula [12]. Our recent studies showed that each integer increase of VAI was associated with a 1.3-fold increased risk of ED in men.

We previously reported a multidisciplinary clinical study investigating the effect of VAl on sexual function in men with high VAl levels. A debate is still open whether male sexual dysfunction could be recovered when the correctable risk factors are adequately managed by dietary control and increased physical activity upon the VAl levels. According to the European Urology Association's guideline on male sexual dysfunction, lifestyle changes are recommended as the first step in managing erectile dysfunction [13]. This study primarily aimed to show whether a decrease of the VAl affects sexual function in male patients with and without metabolic syndrome by managing lifestyle changes such as increased daily activity and dietary control. The secondary outcome was to ascertain whether controlling the MeTS can help to improve sexual functions.

\section{Methods}

After obtaining the Institutional Board approval of the Ondokuz Mayıs University Local Ethics Committee (Approval no: B.30.2.ODM.0.20.08/524), this prospective study was conducted among patients at outpatient urology clinic at one center. Written informed consent was obtained from the participants. After a power analysis was performed, a total of 79 sexually active men out of the 128 participants with complete data were recruited in two groups: Patients with MeTS $(n=48)$ and Patients with no MeTS $(n=$ 31). Those with incomplete data $(n=29)$, active neurological disorders $(n=8)$, psychiatric diseases $(n=$ $4)$, end-stage renal failure $(n=3)$, those with a history of total thyroidectomy $(n=2)$ and patients with urogenital cancer surgery $(n=4)$ were excluded from the study (Fig. 1). Participants were given the Turkish-validated 15-items long-form of the International Index of Erectile Dysfunction (IIEF) questionnaire to fill. Erectile function was assessed using the IIEF 1-5 and 15th items; sexual satisfaction, orgasmic function, sexual desire and general satisfaction were assessed using the IIEF 68th, 9-10th, 11-12th, and 13-14th items, respectively. Participants with IIEF 1-5 and 15 scores $\geq 26$ were defined as non-ED patients, those with IIEF $1-5$ and 15 score $=22-25$ were mild ED, IIEF $1-5$ and 15 scores $=17-21$ were mild-to-moderate ED, IIEF $1-5$ and 15 scores $=11-16$ were moderate ED, and IIEF $1-$ 5 and 15 scores $=0-10$ were defined as severe ED. The Beck's depression inventory (BDI), one of the most 
commonly used tools for the self- measure of emotional, cognitive, somatic, and motivational components, was used for identification of psychological statuses of the patients as no depression ( $<13$ pts), minimal-moderate depressive symptoms (range 14-19), moderate-severe depressive symptoms (range 20-29), and severe depressive symptoms (range 30-63) [14]. A score of less than 14 was considered of no depression. The BDI assessment was performed at the first visit only. Male sex-specific VAl was calculated using [(WC / 39.68) + (1.88 x MI)] x TG / $1.03 \times 1.31$ / HDL formula [12]. For VAl, body mass index (BMI) was calculated using the $\mathrm{kg} / \mathrm{m}^{2}$ formula, and waist circumference (WC) measurement was performed at the level of the umbilicus. The mean age of the patients and comorbidities, including hypertension and diabetes mellitus, medications, smoking and duration of ED, were recorded. Using the enzyme-linked immunosorbent assay (ELISA), single hormonal analysis for total T, prolactin (PRL), estradiol $\left(E_{2}\right)$ tests were performed from morning fasting venous blood samples. According to the Endocrine Society, Clinical Practice Guideline and European Association of Urology Guidelines in Male Hypogonadism and the American Urological Association, guidelines on $\mathrm{T}$ deficiency range for $\mathrm{T}$ are given between $264 \mathrm{ng} / \mathrm{dL}$ and $350 \mathrm{ng} / \mathrm{dL}$, and below $300 \mathrm{ng} / \mathrm{dL}(12.13 \mathrm{nmol} / \mathrm{L})$ as a reasonable cutoff (moderate recommendation; evidence level: grade B) $[6,15]$. The T/ E2 formula measured the testosterone (T) and estradiol (E2) ratio.

The mean sexual satisfaction, orgasm, desire and general satisfaction scores were calculated using the long form of the IIEF questionnaire. Metabolic syndrome criteria are described according to the National Cholesterol Education Program [16]. Patients having at least three of the following components were identified MeTS.

1. A waist circumference of greater than $102 \mathrm{~cm}$,

2. Triglyceride level higher than $150 \mathrm{mg} / \mathrm{dL}$, or receiving treatment for hypertriglyceridemia,

3. $\mathrm{HDL}$ cholesterol of less than $40 \mathrm{mg} / \mathrm{dL}$,

4. Systolic blood pressure higher than $130 \mathrm{~mm} \mathrm{Hg}$, or diastolic blood pressure higher than $85 \mathrm{~mm} \mathrm{Hg}$, or receiving antihypertensive treatment

5. Fasting glucose level greater than $100 \mathrm{mg} / \mathrm{dL}$, or receiving treatment for hyperglycemia.

Participants were advised to 8500 steps per day and dietary control, antihyperlipidemic treatment and diabetic control when necessary [17]. The patients were followed up for at least three months. None of the participants were given oral or interventional therapy for ED. The BMI, WC, triglyceride and HDLcholesterol levels and demographic, anthropometric and biochemical tests were repeated at the followup.

We recorded median VAI levels, erectile function, sexual satisfaction, orgasm, desire, and overall satisfaction scores between the first and the last visit. The impact of dietary control and increased physical activity on metabolic control, VAI and sexual functions were analyzed. Associations between changes of the VAl and all individual sexual domains were compared.

\section{Statistical Analysis}


The Kolmogorov Smirnov test analyzed continuous variables of the cases with normal distribution. Age, height, weight, BMI and WC were presented as arithmetic mean \pm standard deviation, and variables that did not fit the normal distribution were presented as median and Interquartile Range (IQR). Wilcoxon, Paired T, and McNemar tests were used to analyze the data of dependent groups, and Student's t-test, Mann-Whitney $\mathrm{U}$ test, and Chi-square tests were used to compare independent groups.

\section{Results}

Each integer increase of the VAI scores increased the risk of the presence of ED 1.07 times in patients without MeTS and increased the ED risk 1.74 times in those with MeTS. The MeTS were diagnosed in 31 $(39.2 \%)$ cases with a mean age of $55.1 \pm 8.3$ years. The distribution of clinical and laboratory findings according to the diagnosis of MeTS is given in Table 1. The median follow-up interval was four months (3-4) in patients with no MeTS and four months (4-5) in those with MeTS.

Thirty-three (41.8\%) of the participants were nonsmokers, 21 (26.6\%) reported that they had quit, and 25 $(31.6 \%)$ were current smokers. The rates of current smokers were $45.8 \%$ and $76.4 \%$ in patients without and with MeTS, respectively $(X 2=7.73 ; p=0.021)$. Comorbid diseases were also higher in cases diagnosed with MeTS than those without MeTS (Table 2). The rate of taking medication was significantly higher in patients with MeTS than those without MeTS (67.7\% vs $16.7 \%, \mathrm{X} 2=21.2, \mathrm{p}<0.001)$. Moderate to severe ED rates were higher in patients with MeTS than those with no MeTS $(80.6 \%$ vs $58.3 \%, X 2=4.25, p=0.033)$.

Regardless of the groups, the mean VAI of 79 patients was $7.1 \pm 4.6$ at the first visit and significantly decreased to $6.41 \pm 7.7$ at the end of the follow-up period $(z=2.50 ; p=0.012)$. The mean VAl value slightly increased by $5 \%$ in patients without MeTS $(t=0.23, p=0.823)$ but significantly decreased by $24 \%$ in patients with MeTS at the end of the follow-up period compared to first admission ( $t=2.62, p=0.014)$ (Table 3). In eight patients, the MeTS criteria were disappeared at the end of the study (25.8\%), and in those patients, the mean VAl slightly decreased to $6.0 \pm 3.6$ from $7.4 \pm 3.8(z=1.78 ; p=0.07)$.

At the beginning of the study, patients with MeTS and no-MeTS showed similar sexual satisfaction, orgasm, desire, and general satisfaction scores. Although erectile function score was slightly higher in the non-MeTS arm, both groups had mild erectile dysfunction scores. Patients with no MeTS had significant improvements in sexual satisfaction, orgasm and general satisfaction, whereas desire score remained stable. Patients with MeTS showed no improvement for sexual satisfaction, desire, orgasm and general satisfaction scores. Changes in sexual functions in each group are given in Table 4. Considering the sexual functions, controlling the METS slightly improved sexual satisfaction, general satisfaction and desire scores, but deterioration of median orgasm and erectile function scores (Table 5).

Regardless of the groups, dietician-controlled diet and sportive activity decreased the median VAl scores in $63 \%$ of the patients, and all sexual function scores and the median VAl scores significantly improved $(p<0.05)$ (Table 6). 
The median T levels were slightly lower in the MeTS arm at the beginning of the study $(p=0.999)$, although within normal limits in both groups, and T levels showed a slight increase in both groups at the end of the study $(p>0.05)$.

\section{Discussion}

To the best of our knowledge, the present study is the first in the English literature to investigate the effect of VAI control on sexual function in men through lifestyle changes, including dietary control and increased physical activity. Lifestyle changes have been shown to reduce adipose tissue burden, decrease the inflammatory response [18] and suppress peripheral aromatization [19]. Controlling the metabolic status and body weight has been shown a proportional increase of serum testosterone [20].

Although many studies showed a relationship between obesity and ED, only a few studies have demonstrated that the VAI could homogeneously predict adipose tissue dysfunction than BMI and waist circumference [12,21]. Recent studies showed that an increase of VAl level is linked with a 1.2 to 1.4 fold increased risk of ED [22,23].

We previously reported that the VAl could be an independent risk factor for ED. However, the MeTS was not taken into consideration in that study. The current study showed that each integer increase in VAI was associated with an increased risk of ED in the MeTS arm only, compared to those without MeTS (odds ratios $=1.74$ and 1.07, respectively) [12]. The MeTS arm showed a significant decrease in VAI, but other sexual function scores remained similar, whereas the IIEF score improved. The MeTS may contribute to men's sexual dysfunction with more complicating components, including dyslipidemia, hypertension and diabetes mellitus [24]. Physical activity improves ED by improving endothelial dysfunction, increasing endothelial-derived nitric oxide, decreasing oxidative stress and increasing apoptotic circulating endothelial progenitor cells $[25,26,27]$. Our results showed that lifestyle changes improved the MeTS criterion in one out of every four MeTS cases. Still, the fact that sexual function scores remained similar might indicate that a complex pathology such as MeTS contributes more likely to male sexual dysfunction. Our findings showed that lifestyle changes were related to significant improvement in all sexual function scores among the non-MeTS patients despite the mean VAl levels being similar at the beginning of the study. Maio et al. stated that physical activity was an independent variable for erectile function and better sexual satisfaction [28]. However, there is no data on this study related to MeTS. Crisostomo et al. commented that dietary control failed to correct testicular damage by inducing irreversible changes in pyruvate and glutamate metabolism, ethanol degradation and ammonia recycling. Although the metabolic status was corrected, there was no improvement in sperm quality [29]. The present study showed that the MeTS group more widely adopted recommendations for lifestyle changes; only a slight improvement was observed in the erectile function scores, but the IIEF scores remained within the mild ED limits.

Whereas significant improvement was observed in other sexual functions and IIEF scores in the NonMeTS arm. However, it is hard to comment whether this was due to the biochemical changes mentioned 
or secondary to androgen levels; hence, androgen level was not evaluated at the end of the study. Measurement was not made because the groups' androgen level was within normal limits. According to the American Urological Association, the Endocrine Society Clinical Practice Guideline, and European Association of Urology guidelines, hyperandrogenism is defined when $\mathrm{T}$ is below $300 \mathrm{ng} / \mathrm{dL}$ and between $264 \mathrm{ng} / \mathrm{dL}$ and $350 \mathrm{ng} / \mathrm{dL}$, respectively [6,30]. However, this is a limiting definition with a moderate recommendation and a grade B evidence level [15]. Because some symptomatic men with T levels above this limit may experience sexual dysfunction with the contribution of psychogenic and metabolic risk factors.

Moreover, some men may not have sexual dysfunction despite T levels below this level. A slight decrease of mean T concentration in the MeTS arm may be due to hypogonadism triggered by inflammatory molecules secreted from the increased adipose tissue. Indeed, leptin production has increased in obese individuals, which plays a regulatory role and homeostasis in physiological amounts. An increased amount of leptin inhibits the stimulating effect of gonadotropins on Leydig cells of the testis, leading to hypogonadism [31]. Lack of measurement of leptin activity is also one of the limiting factors in the present study.

Erectile dysfunction and decreased libido may occur secondary to decreased circulating $T$ levels in response to hypogonadism and due to peripheral aromatization of $T$ to $E 2$ [32]. Increased conversion of $T$ to $E_{2}$ in excessive adipose tissue via increased aromatase activity may also decrease the circulating level of T and may consequently cause ED [33]. As shown in Table 1, although nonsignificant, T/E2 was slightly reduced. From this point of view, it can be assumed that peripheral aromatization is not the sole reason for ED. Still, it may contribute to ED. Our opinion is that the decrease in serum T, albeit slightly, may be related to suppressed gonadotropic stimulation and converting $T$ to $E 2$ in peripheral adipose tissue.

Increased physical activity has increased self-esteem and supported mental health upon psychological issues [34]. In a meta-analysis, seven randomized-controlled trials showed that physical activity more than average might be beneficial for erectile function. They might reverse the ED process, but the MeTS was not handled in that report [35]. In a study of 65 men with the MeTS, 35 were assigned to dietary restriction, and 30 were to control diet. The authors assessed only erectile function, and a significant increase of IIEF score was achieved in the diet group [36].

Critical discussion should focus on why there is no improvement in sexual functions other than EF in patients with MeTS. Possibly, this may be related to chronic states such as heart disease, hypertension, stroke, diabetes and obesity, mental states such as anxiety and depression, lifestyle factors including the sedentary lifestyle and decreased physical activity [37]. Almost half of type 2 diabetic men suffer from ED, and as age increases, its prevalence rises to 75\% [38]. Recently it was reported that microvascular damage might result in a decrease of blood supply to the nerves. Glial cells and neurons are affected at first, and vascular endothelial damage develops afterward [39]. Specifically, hypertension was shown to increase levels of angiotensin II, which provokes reactive oxygen species (ROS). The increased amount of 
ROS reduces nitric oxide levels [40]. Not only the presence of hypertension but also common side-effects of many antihypertensive agents such as b-blockers and diuretics may contribute to ED [41]. The presence of a high number of comorbidities causing the MeTS may adversely affect patients' general health status, and it may add to poor overall health and consequent sexual dysfunction [42]. The mean BDI scores were within normal limits ( $<14$ points) in patients with MeTS compared to those without MeTS. Therefore, in our study, we thought that depressive symptoms did not contribute to sexual dysfunction among the groups.

Limitations of this Study

1. An only a single measurement of $T$ and enzyme-linked immunosorbent assay.

2. Lack of assessment of the penile vascular system using penile duplex ultrasonography.

3. Lack of measurement of cytotoxic end-products such as leptin, adipokine which may interfere with endothelial function.

4. A relatively low number of participants.

\section{Conclusions}

Lifestyle changes led to improvement in all sexual function scores in men, regardless of the presence of MeTS. However, a higher mean VAl level was associated with lower erectile function scores, particularly in patients with MeTS. Lifestyle changes, such as increased physical activity and dietary control improved other male sexual function scores including erectile function, only in patients with no MeTS. Still, no improvement was achieved in sexual function by lifestyle changes, despite the MeTS criterion being eliminated in one out of four patients with MeTS. Our results showed that sexual dysfunction in men with no MeTS could be managed more effectively than men with MeTS, and fighting against MeTS should be adopted as a global healthcare policy.

\section{Declarations}

Data generated or analyzed during this study can be reached from the corresponding author.

\section{Conflicts of Interest:}

The authors report no conflicts of interest.

\section{Funding:}

None.

\section{Author contributions}


MSB, RA: Conceived and designed the work that led to the submission, acquired data,

and/or played an important role in interpreting the results.

FK, MLÖ, BŞ, MY, SSG, CD: Drafted or revised the manuscript.

MSB, RA, FK, MLÖ, BŞ, MY, SSG, CD: Approved the final version.

MSB, RA, CD: Agreed to be accountable for all aspects of the work in ensuring that

questions related to the accuracy or integrity of any part of the work are appropriately

investigated and resolved.

\section{References}

1. Mulhall J, Teloken P, Brock G, Kim E. Obesity, dyslipidemias and erectile dysfunction: a report of a subcommittee of the sexual medicine society of North America. J Sex Med 2006;3:778-786.

2. McCabe MP, Sharlip ID, Lewis R, Atalla E, Balon R, Fisher AD, et al. Incidence and Prevalence of Sexual Dysfunction in Women and Men: A Consensus Statement from the Fourth International Consultation on Sexual Medicine 2015. J Sex Med. 2016;13(2):144-52.

3. Bolat MS, Kocamanoglu F, Ozbek ML, Buyukalpelli R, Asci R. Can High Visceral Adiposity Index Be a Risk Factor for Sexual Dysfunction in Sexually Active Men? J Sex Med. 2020;17(10):1926-1933. doi: 10.1016/j.jsxm.2020.06.014.

4. Sanchez E, Pastuszak AW, Khera M. Erectile dysfunction, metabolic syndrome, and cardiovascular risks: facts and controversies. Transl Androl Urol. 2017 Feb;6(1):28-36.

5. Maiorino MI, Bellastella G, Esposito K. Lifestyle modifications and erectile dysfunction: what can be expected? Asian Journal of Andrology. 2015;17, 5-10.

6. Dohle GR, Arver S, Bettocchi C, et al. Male hypogonadism. Available at: https://uroweb.org/guideline/malehypogonadism/Accessed October 31, 2019.

7. Gökçe Mi, Yaman Ö. Erectile dysfunction in the elderly male. Turk J Urol. 2017;43(3):247-251.

8. Wang TD, Lee CK, Chia YC, Tsoi K, Buranakitjaroen P, Chen CH, et al. the HOPE Asia Network. Hypertension and erectile dysfunction: The role of endovascular therapy in Asia. J Clin Hypertens. 2021;23:481-488.

9. Elsaied MA, Masallat D, Abdel-Hamid IA. Correlation of Adiponectin With Testosterone in Patients With and Without Type 2 Diabetes and Erectile Dysfunction. Am J Men's Health. 2019;13(1):1557988318807049.

10. Patel P, Abate N. Body fat distribution and insulin resistance. Nutrients. 2013;5(6):2019-2027.

11. Hannan JL, Maio MT, Komolova M, Adams MA. The beneficial impact of exercise and obesity interventions on erectile function and its risk factors. J Sex Med. 2009;6(3):254-61. 
12. Amato MC, Giordano C, Galia M, Criscimanna A, Vitabile S, Midiri M, et al. Visceral Adiposity Index: a reliable indicator of visceral fat function associated with cardiometabolic risk. Diabetes Care. 2010;33:920-922.

13. Salonia A, Bettocchi C, Carvalho J, Corona G, Jones TH, Kadioglu A, et al. (Guidelines Associates: Boeri L, Capogrosso P, Cocci A, Dimitropoulos K, Gül M, Hatzichristodoulou G, Kalkanli A, Modgil V, Milenkovic U, Russo G, Tharakan T. EAU Guidelines on Sexual and Reproductive Health, 2021.

14. Beck AT, Steer RA, Brown GK. Manual for the Beck Depression Inventory second edition (BDI-II). The Psychological Corporation; 1996.

15. Morgentaler A, Traish AM, Khera M. A critique of the AUA guidelines on testosterone deficiency. J Sex Med 2020; 17:561e564.

16. (NCEP ATP3, 2005) Thomas GN, Ho SY, Janus ED, Lam KS, Hedley AJ, Lam TH. Hong Kong Cardiovascular Risk Factor Prevalence Study Steering Committee. The US National Cholesterol Education Programme Adult Treatment Panel III (NCEP ATP III) prevalence of the metabolic syndrome in a Chinese population. Diabetes Res Clin Pract. 2005;67(3):251-7.

17. Burton HM. Coyle EF. Daily Step Count and Postprandial Fat Metabolism, Medicine \& Science in Sports \& Exercise: February 2021 - Volume 53 - Issue 2 - p 333-340.

18. Giugliano D, Ceriello A, Esposito K. The Effects of Diet on Inflammation: Emphasis on the Metabolic Syndrome. Journal of the American College of Cardiology. 2006;48 (4):677-685.

19. Giagulli VA, Castellana M, Murro I, Pelusi C, Guastamacchia E, Triggiani V, et al. The Role of Diet and Weight Loss in Improving Secondary Hypogonadism in Men with Obesity with or without Type 2 Diabetes Mellitus. Nutrients. 2019;11(12):2975.

20. Singh A and Dobs AS. Is it Time to Test the Effect of Weight Loss on Testosterone? Clinical Chemistry. 2019;65(1):48-50.

21. Maio MT, Hannan JL, Komolova M, Adams MA, The caloric restriction prevents visceral adipose tissue accumulation and maintains erectile function in ageing rats. J Sex Med. 2012;9(9):2273-83.

22. Akdemir AO, Karabakan M, Aktas BK, Bozkurt A, Ozgur EG, Akdogan N, et al. Visceral adiposity index is useful for evaluating obesity effect on erectile dysfunction. Andrologia. 2019 Jul;51(6):e13282.

23. Bolat MS, Ozbek ML, Şahin B, Yılmaz M, Kocamanoglu F, Buyukalpelli R, et al. Impact of high visceral adiposity index associated with metabolic syndrome on erectile function in sexually active men: Results of a cross-sectional study. Int J Clin Pract. 2021;75(6):e14111.

24. Rew KT, Heidelbaugh JJ. Erectile Dysfunction. Am Fam Physician. 2016;94(10):820-827.

25. Meldrum DR, Gambone JC, Morris MA, Esposito K, Giugliano D, Ignarro LJ. Lifestyle and metabolic approaches to maximizing erectile and vascular health. Int J Impot Res 2012;24: 61-8.

26. Meldrum DR, Burnett AL, Dorey G, Esposito K, Ignarro LJ. Erectile hydraulics: maximizing inflow while minimizing outflow. J Sex Med. 2014;11:1208-20.

27. van Craenenbroeck EM, Conraads VM. Endothelial progenitor cells in vascular health: focus on lifestyle. Microvasc Res. 2010;79:184-92. 
28. Maio G, Saraeb S, Marchiori A. Physical activity and PDE5 inhibitors in the treatment of erectile dysfunction: results of a randomized controlled study. J Sex Med. 2010;7:2201-8.

29. Crisóstomo L, Rato L, Jarak I, Silva BM, Raposo JF, Batterham RL, et al. Switching from a high-fat diet to a regular diet does not restore sperm quality but prevents metabolic syndrome. Reproduction. 2019;158(4):377-387.

30. Bhasin S, Brito JP, Cunningham GR, Hayes FJ, Hodis HN, Matsumoto AM, et al. Testosterone Therapy in Men With Hypogonadism: An Endocrine Society Clinical Practice Guideline. J Clin Endocrinol Metab. 2018; 103:1715-1744.

31. Fernandez CF, Chacko EC, Pappachan JM. Male obesity-related secondary hypogonadismepathophysiology, clinical implications and management. Eur Endocrinol 2019;15:8390.

32. Zitzmann M, Faber S, Nieschlag E. Association of specific symptoms and metabolic risks with serum testosterone in older men. J Clin Endocrinol Metab. 2006;91:4335-4343.

33. Schulster ML, Liang SE, Najari BB. Metabolic syndrome and sexual dysfunction. Curr Opin Urol. 2017;27(5):435-440.

34. Cooney GM, Dwan K, Greig CA, Lawlor DA, Rimer J, Waugh FR,et al. Exercise for depression. Cochrane Database Syst Rev 2013;9:CD004366.

35. Cheng JY, Ng EM, Ko JS, Chen RY. Physical activity and erectile dysfunction: a meta-analysis of population-based studies. Int J Impot Res. 2007;19(3):245-52.

36. Esposito K, Ciotola M, Giugliano F, De Sio M, Giugliano G, D'armiento M, et al. Mediterranean diet improves erectile function in subjects with the metabolic syndrome. Int J Impot Res 2006;18:40510.

37. Schlichthorst M, Sanci LA, Hocking JS. Health and lifestyle factors associated with sexual difficulties in men - results from a study of Australian men aged 18 to 55 years. BMC Public Health. 2016;16(3):1043.

38. Vickers MA, Wright EA. Erectile dysfunction in the patient with diabetes mellitus. Am J Managed Care 2004;10:S3-S11.

39. Forbes JM, Cooper ME. Mechanisms of diabetic complications. Physiol Rev. 2013;93:137-188.

40. Jin L, Lagoda G, Leite R, Webb RC, Burnett AL, et al. NADPH oxidase activation: a mechanism of hypertension-associated erectile dysfunction. J Sex Med 2008;5:544-551.

41. Papatsoris AG, Korantzopoulos PG. Hypertension, antihypertensive therapy, and erectile dysfunction. Angiology 2006;57:47-52.

42. Laumann EO, Nicolosi A, Glasser DB, Paik A, Gingell C, Moreira E, et al. Sexual problems among women and men aged 40-80 y: prevalence and correlates identified in the global study of sexual attitudes and behaviours. Int J Impot Res. 2005;17(1):39-57.

\section{Tables}


Table 1

Demographic, clinic and biochemical characteristics of the patients according to metabolic syndrome (MeTS).

\begin{tabular}{|c|c|c|c|c|}
\hline & $\begin{array}{l}\text { Patients with no } \\
\text { MeTS } \\
(\mathrm{n}=48)\end{array}$ & $\begin{array}{l}\text { Patients with } \\
\text { MeTS }(n=31)\end{array}$ & $\mathrm{t}$ & p \\
\hline Age $^{\star}$ (Years) & $49.5 \pm 12.2$ & $55.1 \pm 8.3$ & 2.39 & 0.019 \\
\hline $\begin{array}{l}\text { Body mass index* } \\
\left(\mathrm{Kg} / \mathrm{m}^{2}\right)\end{array}$ & $28.8 \pm 4.5$ & $29.6 \pm 4.8$ & 0.75 & 0.459 \\
\hline $\begin{array}{l}\text { Median follow-up } \\
\text { period (month) }\end{array}$ & $4-5$ & $3-4$ & - & - \\
\hline HDL-cholesterol* & $50.3 \pm 2.2$ & $39.4 \pm 1.6$ & 4.43 & $<0.001$ \\
\hline Triglyceride* & $136.3 \pm 15.6$ & $213.0 \pm 21.9$ & 1.63 & 0.108 \\
\hline IIEF** score & $14(10-19)$ & $10(5-14)$ & 2.14 & 0.033 \\
\hline $\begin{array}{l}\text { Duration of } \\
\text { erectile dysfunction } \star \star \star \\
\text { (month) }\end{array}$ & $12(6-24)$ & $7(6-42)$ & 0.26 & 0.793 \\
\hline Beck depression score & $7.6 \pm 3.9$ & $9.8 \pm 5.6$ & 0.76 & 0.431 \\
\hline 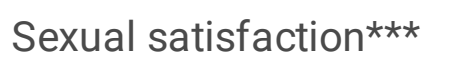 & $7(4-9)$ & $4.5(3-8)$ & 1.16 & 0.246 \\
\hline
\end{tabular}



Orgasm ${ }^{\star \star \star}$
$6(3-8)$
$3.5(1-7)$
0.56
0.574

$\begin{array}{lllll}\text { Desire }^{\star \star \star} & 4(3-7) & 4(3-7) & 1.12 & 0.261\end{array}$

$\begin{array}{lllll}\text { General satisfaction }^{\star \star *} \quad 4(3-7) & 4(3-5) & 0.64 & 0.522\end{array}$

$\begin{array}{lllll}\begin{array}{l}\text { Total testosterone } \\ (\mathrm{ng} / \mathrm{dL})\end{array} & 440(360-640) & 390(300-460) & 0.02 & 0.099\end{array}$

\begin{tabular}{lllll}
\hline Prolactin $(\mathrm{mg} / \mathrm{L})$ & $9.5(7.7-12.3)$ & $9.4(7.4-15.9)$ & 0.72 & 0.477 \\
\hline $\begin{array}{l}\text { Visceral adiposity } \\
\text { index* }\end{array}$ & $4.2 \pm 0.6$ & $8.1 \pm 0.9$ & 3.29 & $\mathbf{0 . 0 0 2}$ \\
\hline
\end{tabular}

\section{Estradiol $(\mathrm{pg} / \mathrm{mL})$}

$$
25.8(21.1-33.2)
$$

$26.2(21.8-36.2)$

0.46

0.646

$\mathrm{T} / \mathrm{E}_{2}$ ratio

$20.7 \pm 13.6$

$18.2 \pm 12.6$

$z=0.75$

0.450

Diabetes mellitus (n, \%) 4 (8.3)

15 (48.4)

16.5

$<0.001$

Hypertension
$(\mathrm{n}, \%)$
$5(10.4)$
14 (45.2)
12.5
0.001
Coronary artery disease $\quad 3(6.3)$ $(n, \%)$
9 (29.0)
7.59
0.009

Smoking volume (pack/year) 
*(mean \pm standard deviation), $\star * \mid I E F:$ International Index of Erectile Function, ***mean (min-max).

\section{Table 2}

Distribution of comorbidities according to the presence of MetS.

\begin{tabular}{lllcc} 
Diagnosis/Treatment & MetS (-) & Mets (+) & $\mathbf{X}^{2}$ & p \\
& $\mathbf{n}(\%)$ & $\mathbf{n}(\%)$ & & \\
\hline Diabetes mellitus & $4(8.3)$ & $15(48.4)$ & 16.5 & $<0.001$ \\
\hline Hypertension & $5(10.4)$ & $14(45.2)$ & 12.5 & $\mathbf{0 . 0 0 1}$ \\
\hline Coronary artery disease & $3(6.3)$ & $9(29.0)$ & 7.59 & $\mathbf{0 . 0 0 9}$
\end{tabular}

Table 3

Changes of the visceral adiposity index (VAl) according to presence of metabolic syndrome Metabolic syndrome Visceral adiposity index

\begin{tabular}{lllll} 
& First visit & Last Visit & $\mathbf{t}$ & $\mathbf{p}$ \\
\hline No & $5.7 \pm 3.8$ & $6.0 \pm 9.3$ & 0.23 & 0.823 \\
\hline Yes & $9.2 \pm 5.0$ & $7.0 \pm 2.7$ & 2.62 & $\mathbf{0 . 0 1 4}$
\end{tabular}




\section{Table 4}

Changes of sexual functions in groups throughout the study.

Sexual Function Patients with no MeTS* (48)

Patients with MeTS (31)

\begin{tabular}{|c|c|c|c|c|c|c|}
\hline & First Visit & Last Visit & p & First Visit & Last Visit & p \\
\hline $\begin{array}{l}\text { Sexual } \\
\text { satisfaction }\end{array}$ & $6.0(3.0-8.5)$ & $\begin{array}{l}8.0(5.0- \\
10.0)\end{array}$ & 0.015 & $\begin{array}{l}6.0(2.0- \\
8.0)\end{array}$ & $7.0(2.0-8.0)$ & 0.125 \\
\hline $\begin{array}{l}\text { General } \\
\text { satisfaction }\end{array}$ & $4.0(2.5-6.5)$ & $6.0(4.0-8.0)$ & 0.018 & $4.0(3.0-6.0)$ & $4.0(2.0-7.0)$ & 0.170 \\
\hline Desire & $5.0(4.0-7.5)$ & $6.0(4.0-8.0)$ & 0.333 & $4.0(3.0-7.0)$ & $4.0(4.0-7.0)$ & 0.063 \\
\hline Orgasm & $5.0(2.5-8.0)$ & $6.0(4.0-9.0)$ & 0.028 & $4.0(2.0-7.0)$ & $5.0(3.0-7.0)$ & 0.396 \\
\hline Erectile function & $\begin{array}{l}13.0(10.0- \\
19.0)\end{array}$ & $\begin{array}{l}15.5(9.0- \\
21.5)\end{array}$ & 0.001 & $\begin{array}{l}12.0(6.0- \\
15.0)\end{array}$ & $\begin{array}{l}15.0(9.0- \\
18.0)\end{array}$ & 0.008 \\
\hline
\end{tabular}

*MeTS, metabolic syndrome

\section{Table 5}

Changes in sexual functions in patients with metabolic syndrome at the end of the study.

Patients with metabolic syndrome

\begin{tabular}{|lllll|}
\hline Sexual Function (median, min-max) & $\begin{array}{l}\text { Corrected } \\
(\mathbf{n = 8})\end{array}$ & Uncorrected $(\mathbf{n}=\mathbf{2 3})$ & $\mathbf{z}$ & $\mathbf{p}$ \\
\hline Sexual Satisfaction & $7(5-8.5)$ & $6.5(2-8)$ & 0.78 & 0.447 \\
\hline General satisfaction & $4.5(3-5.5)$ & $4(2-7)$ & 0.02 & 0.982 \\
\hline Desire & $5.5(4-8)$ & $4.5(4-6)$ & 1.10 & 0.298 \\
\hline Orgasm & $5(2.5-7.5)$ & $5.5(3-7)$ & 0.02 & 0.982 \\
\hline Erectile function & $13.5(12-18.5)$ & $15(8-18)$ & 0.34 & 0.740 \\
\hline
\end{tabular}




\begin{tabular}{|c|c|c|c|c|}
\hline \multicolumn{5}{|c|}{$\begin{array}{l}\text { Regardless of the groups, dietary restriction and increased sportive activity improve all sexual } \\
\text { functions. }\end{array}$} \\
\hline & Scores & & & \\
\hline & First Visit & Last Visit & $\mathbf{z}$ & $\mathrm{p}$ \\
\hline Erectile function & $12.5(6-18)$ & $17(9-22)$ & 4.43 & $<0.001$ \\
\hline Sexual satisfaction & $6(2-8)$ & $7(4-9)$ & 2.93 & 0.003 \\
\hline Orgasm & $5(2-7)$ & $6(4-8)$ & 2.58 & 0.010 \\
\hline Desire & $4(3-7)$ & $6(4-8)$ & 2.02 & 0.043 \\
\hline General satisfaction & $4(2-6)$ & $5(3-8)$ & 3.20 & 0.001 \\
\hline Visceral adiposity index & $7.08 \pm 4.6$ & $6.41 \pm 7.7$ & 2.50 & 0.012 \\
\hline
\end{tabular}

\section{Figures}

\section{Image not available with this version}

Figure 1

This image is not available with this version. 